\title{
Dispersion attenuation structure of the crust around the Weifang-Jiashan segment of the Tanlu fault zone in North China*
}

\author{
Xiqiang Liu ${ }^{1, \uparrow}$ Qinghe $\mathrm{Li}^{2}$ and $\mathrm{Hong}^{1}{ }^{1}$ \\ ${ }^{1}$ Earthquake Administration of Shandong Province, Ji'nan 250014, China \\ ${ }^{2}$ Earthquake Administration of Jiangsu Province, Nanjing 210014, China
}

\begin{abstract}
On the condition that the velocity ratio of compressive wave to shear wave is stable during the propagating process of seismic wave, this paper develops an estimation method for medium quality factor based on single station's travel time difference between direct $\mathrm{S}$ and $\mathrm{P}$ waves and the first period signal of direct $\mathrm{P}$ wave. 8774 high SNR wave data altogether recorded by 75 stations are analyzed. The results show that: (1) under the normal regional stress field, the quality factors $Q_{\mathrm{mSP}}$ in the stable tectonic area are higher than that in the active tectonic area around the Weifang-Jiashan section and its surrounding area in the Tanlu fault zone; (2) in the Juxian-Tancheng section the seismic wave attenuation is relatively quick, and the media is relatively broken, suggesting no tectonic stress accumulation; (3) the Xinyi-Sihong section is currently locking and in accumulating elastic strain energy stage, which has the deep environment and conditions of strong earthquake generation similar to those of the 1668 M8.5 Tancheng strong earthquake.
\end{abstract}

Key words: dispersion attenuation; quality factor; measurement method; Tanlu fault zone; seismic risk

CLC number: P315.3 $3^{+}$Document code: A

\section{Introduction}

Rock is fluid-containing porous media, in which irregular porous structure and multiple particle size make the media heterogeneous (Gao and Yang, 2007), inelastic and anisotropic. The attenuation study of seismic waves in fluid-containing porous media is one of effective methods for obtaining the internal structure attributes of the media, which is actually common concern of natural seismology, exploration seismology, acoustics, nondestructive testing and rock mechanics test (Wang et al., 2008; Hao et al., 2009; Liu et al., 2010).

The main content and objectives of petrophysics contain identifying the influence of lithology, porosity, fluid type, fluid saturation and cracks on the

\footnotetext{
* Received 6 October 2011; accepted in revised form 26 December 2011; published 10 February 2012.

* Corresponding author. e-mail: lxq6409@163.com

(c) The Seismological Society of China, Institute of Geophysics, China Earthquake Administration, and Springer-Verlag Berlin Heidelberg 2012
}

propagation of elastic waves, searching for the relation between the Earth physical parameters (e.g., wave velocity and attenuation), rock physical properties (e.g., porosity, saturation level permeability) and exploring the potential new physical phenomena by theory and experiment. With the development of earthquake petrophysics, scholars are deepening their understanding the relation between the dispersion, attenuation of elastic wave velocity and rock physical properties. They hold that rock is a kind of dispersion material, and its elastic wave velocity is dependent on the frequency to some extent and attenuation is influenced by the dispersion, the attenuation becomes strong for the frequency band with wave velocity increasing rapidly. On the other hand, if the attenuation is not so great in the medium (e.g., dry rocks), the dispersion becomes rather weak. A large number of observation experiments showed that the phenomenon that "the wave velocity almost always increases with the frequency" was closely related to the phenomenon that "the wave passing through rocks propagates always attenuating (Wang and Nur, 1990)". 
Therefore, attenuation is a universal phenomenon for the wave propagation in rocks, while dispersion is the intrinsic phenomenon greatly associated with it (White, 1975).

As dispersion and attenuation are closely related intrinsic phenomena, it become a new access to estimate quality factor by studying dispersion of short period $\mathrm{P}$ - or S-wave. The method has already been preliminarily applied in many countries such as Italy (Trong and Granet, 1980), Spain (Correig and Mitchell, 1989), America (Cong et al., 2000) and China (Liu et al., 2005, 2009). Liu et al. $(2005,2009)$ studied the $Q$ value in the Chi-Chi (Jiji) earthquake of Taiwan and the Xiuyan earthquake of Liaoning province, and found the residual changes of $Q$ value had a strong coupling relation with the increase of tectonic stress field in the seismic source area and its adjacent area.

The M9.0 earthquake occurred in the east coast of Honshu, Japan, which could result from the collision and extrusion between the Pacific plate and the Eurasian plate. The earthquake immediately made the Pacific plate underthrust by several meters relative to the Eurasia plate, which will influence the seismic activity in the Tanlu fault zone in China's eastern part. What should be paid attention to is that in some sections of the fault zone, e.g., the north and south sides of the source of Tancheng earthquake with $M 8.5$, the media have been in locking and accumulating stage of elastic strain energy for a long time, already possessing the deep environment and conditions of generation of strong earthquake (Zhang et al., 2007).

The Tanlu fault zone can be divided into three sections from north to south according to its structural properties and the seismicity. The north part includes area from Zhaoxing, Heilongjiang province to Changtu, Liaoning province, and the middle section includes area from Changtu to the south bank of the Huaihe river, while the south section includes area from the south bank of the Huaihe river of Jiashan, Anhui province to Guangji, Hubei province. The middle section has strong seismicity, where the released energy is 3200 times greater than that of the south and north parts. The middle part can be further divided into two sections, i.e., the sub-north section (from Changtu, Liaoning province to Weifang, Shandong province) and the sub-south section (from Weifang to Jiashan, Anhui province) (Institute of Geology, State Seismological Bureau, 1987).

Making use of the records from seismic stations in Shandong, Anhui and Jiangsu provinces, the paper sheds light on potential strong earthquakes in the cen- tral south section and its surrounding area.

\section{Measurement method for dis- persion attenuation}

The dispersion attenuation of seismic waves can be attributed to the inelasticity of media. Compared with the media properties in gestation areas of non-strong earthquakes, those in gestation areas of strong earthquakes have obvious inelastic properties, which behave both as inelasticity related to strain and plasticity. The inelasticity of both the media all hinders the propagation of seismic waves, which is different from wave impedance interface that reflects some seismic waves or changes their propagation direction. Instead, they transform some seismic waves into other forms of energy called seismic wave attenuation.

Cong et al. (2000) put forward the estimation method for quality factor via dispersion and by means of first-cycle signal of the $\mathrm{P}$-wave from local earthquakes. Compared with amplitude attenuation method, the method has following potential advantages. Firstly, due to the complexity of horizontal change in the media structure, the amplitude records of seismic waves can be severely affected by the focusing and defocusing effect. Dispersion attenuation is determined by the first arrival part of seismic waves. Therefore compared with the amplitude attenuation method, the focusing and defocusing effect has a relatively small effect on the result of dispersion attenuation measurement. Secondly, the amplitude attenuation research needs seismic source spectrum, the measurement of which is a rather complex process which can be obtained only when the locations of two earthquakes are close to each other and are recorded by the same instrument at the same station, and need to remove geometry diffusion, inelastic attenuation, site response and amplification effect of seismograph. On the other hand, dispersion research needs only the records of single station. Since the larger the magnitude of an earthquake is, the lower the corner frequency will be. Dispersion measurement needs data of low-magnitude earthquake events. Thirdly, by using the record data of small earthquakes, the dispersion attenuation method can be used to study the heterogeneous characteristics of media within small magnitude range, which means that a large number of seismic data in the tectonic movement region can be used for research. If some recordings from small earthquakes with different epicentral distances and focal depths in tectonic movement region can be obtained, the horizontal and 
vertical variation images of inelastic properties in the media of the tectonic movement region can be gotten. Fourthly, by using the records of small earthquakes, it is possible to avoid the complexity of seismic wave records caused by the surface movement along the seismic fault during large earthquake. Fifthly, if the study is limited to the first-cycle records of the $\mathrm{P}$-wave initial motion, various noise interferences can be effectively avoided.

Liu et al. (2005) improved the estimation method for the seismic wave group velocity delay using firstcycle $\mathrm{P}$-wave records in small earthquakes. The analytic expression formula of the group velocity delay $\Delta t_{\mathrm{g}}$ is summarized as the following:

$$
\begin{aligned}
\Delta t_{\mathrm{g}}=\frac{t}{\pi Q_{\mathrm{m}}}\left[\frac{1}{2} \ln \frac{\left(1+\omega^{2} \tau_{2}^{2}\right)\left(1+\omega_{\mathrm{r}}^{2} \tau_{1}^{2}\right)}{\left(1+\omega^{2} \tau_{1}^{2}\right)\left(1+\omega_{\mathrm{r}}^{2} \tau_{2}^{2}\right)}+\right. \\
\frac{\omega^{2}\left(\tau_{1}^{2}-\tau_{2}^{2}\right)}{\left(1+\omega^{2} \tau_{1}^{2}\right)\left(1+\omega^{2} \tau_{2}^{2}\right)}- \\
\left.\frac{\omega_{\mathrm{r}}^{2}\left(\tau_{1}^{2}-\tau_{2}^{2}\right)}{\left(1+\omega_{\mathrm{r}}^{2} \tau_{1}^{2}\right)\left(1+\omega_{\mathrm{r}}^{2} \tau_{2}^{2}\right)}\right]
\end{aligned}
$$

In the formula, $t$ refers to the $\mathrm{P}$-wave travel time. $Q_{m}^{-1}$ is a constant defined by the flat part of the $Q^{-1}(\omega)$ spectrum bounded by $\tau_{1}^{-1}<\omega<\tau_{2}^{-1}$, the amplitude spectrum, in the smooth part within certain frequency ranges (Liu et al., 1976). $\omega$ refers to angular frequency and $\omega_{\mathrm{r}}$ reference frequency. $\tau_{1}$ and $\tau_{2}$ refer to strain relaxation time under persistent stress and the stress relaxation time under persistent strain, respectively.

Suppose the wave velocity ratio $\gamma_{0}$ in the research area is a constant, then the $\mathrm{P}$-wave travel time $t$ and travel time difference between $\mathrm{P}$ - and S-waves would satisfy the following requirements (Feng, 1981).

$$
t=\frac{t_{\mathrm{S}}-t_{\mathrm{P}}}{\gamma_{0}-1}
$$

Making use of the above two formulae, we can obtain the quality factor $Q_{\mathrm{m}}$ by applying the first-cycle signals of $\mathrm{P}$-wave and travel time difference between $\mathrm{S}$ - and $\mathrm{P}$-waves recorded by single station in small earthquakes. The detailed steps are summarized as follows: (1) We select some small earthquakes recorded by single station close to epicenter and get the data of the first cycle signals of vertical seismograms of direct P-wave; (2) In order to reduce the measurement error, we adopt Newton polynomial insertion value method to resample signal at 1000 points/s instead of the original sampling rate; (3) The Chebyshev approximation of equiripple method is used to filter for the minimization of maximum error. Compared with other filters, Chebyshev criterion have the following advantages: when the designing parameters of different filters are the same, the order of filters is lowest. And when the order is the same, the pass band is most smooth while the attenuation of stop band is the quickest. By using Remez alternative algorithm (Qi, 2005), a group of finite impulse response digital filters of linearphase band pass are designed. The central frequency is $f_{\mathrm{cn}}=1.5+2 n, n=0,1, \cdots, 6$; low boundary frequency of pass band $f_{\ln }=0.5+2 n, n=0,1, \cdots, 6$; high boundary frequency of pass band $f_{\mathrm{hn}}=2.5+2 n, n=0,1, \cdots$, 6 ; low boundary frequency of stop band $f_{\mathrm{zln}}=0.1+2 n$, $n=0,1, \cdots, 6$; high boundary frequency of stop band $f_{\mathrm{zhn}}=2.9+2 n, n=0,1, \cdots, 6$; variation coefficient of pass band is $0.01 \mathrm{~dB}$, and minimum attenuation of stop band $A_{t}=80 \mathrm{~dB}$. The sampling rate for data are $f_{\mathrm{s}}=50$ sps and $f_{\mathrm{s}}=100 \mathrm{sps}$, respectively. Then, the remezord and remez function design provided in the Matlab system is used to obtain the above coefficients of band-pass filters. And the filtering results can be gained after the coefficients are convolved with the observation data; (4) The arrival time $t_{n}$ of different group velocities can be obtained according to the maximum peak values of multiple filtering. In most cases, we select $t_{\mathrm{r}}$ that corresponds to central frequency $f_{\mathrm{r}}=7.5 \mathrm{~Hz}$ as arrival time. Then the group velocity delay is $\Delta t_{\mathrm{g}}$, which is worked out by $t_{n}-t_{\mathrm{r}}$; (5) The non-linear Gauss-Newton method is applied to invert $Q_{\mathrm{m}}$ as well as the estimation error below $95 \%$ confidence level (Liu et al., 2005).

\section{Dispersion measurement result}

\subsection{Data}

We collect seismic wave data of small earthquakes recorded in 122 stations and earthquake catalogues from 2001 to August 2011 in Shandong Digital Seismic Network, from 2001 to 2009 in Jiangsu Digital Seismic Network and from 2001 to 2009 in Anhui Digital Seismic Network. The study area covers $30.0^{\circ} \mathrm{N}-38.5^{\circ} \mathrm{N}$ and $115.0^{\circ} \mathrm{E}-123.0^{\circ} \mathrm{E}$ (Figure 1 ), in which no earthquakes above 5.0 magnitude from 2001 to 2011 took place. In order to obtain the special distribution characteristics for dispersion attenuation of seismic waves and its time variation characteristics in the surrounding area, for some stations which are located in the Tanlu fault zone and its vicinity, we select some earthquakes whose epicentral distances are mainly less than $100 \mathrm{~km}$, while for the other stations, we select some earthquakes whose epicentral distances are mainly less than $30 \mathrm{~km}$. 


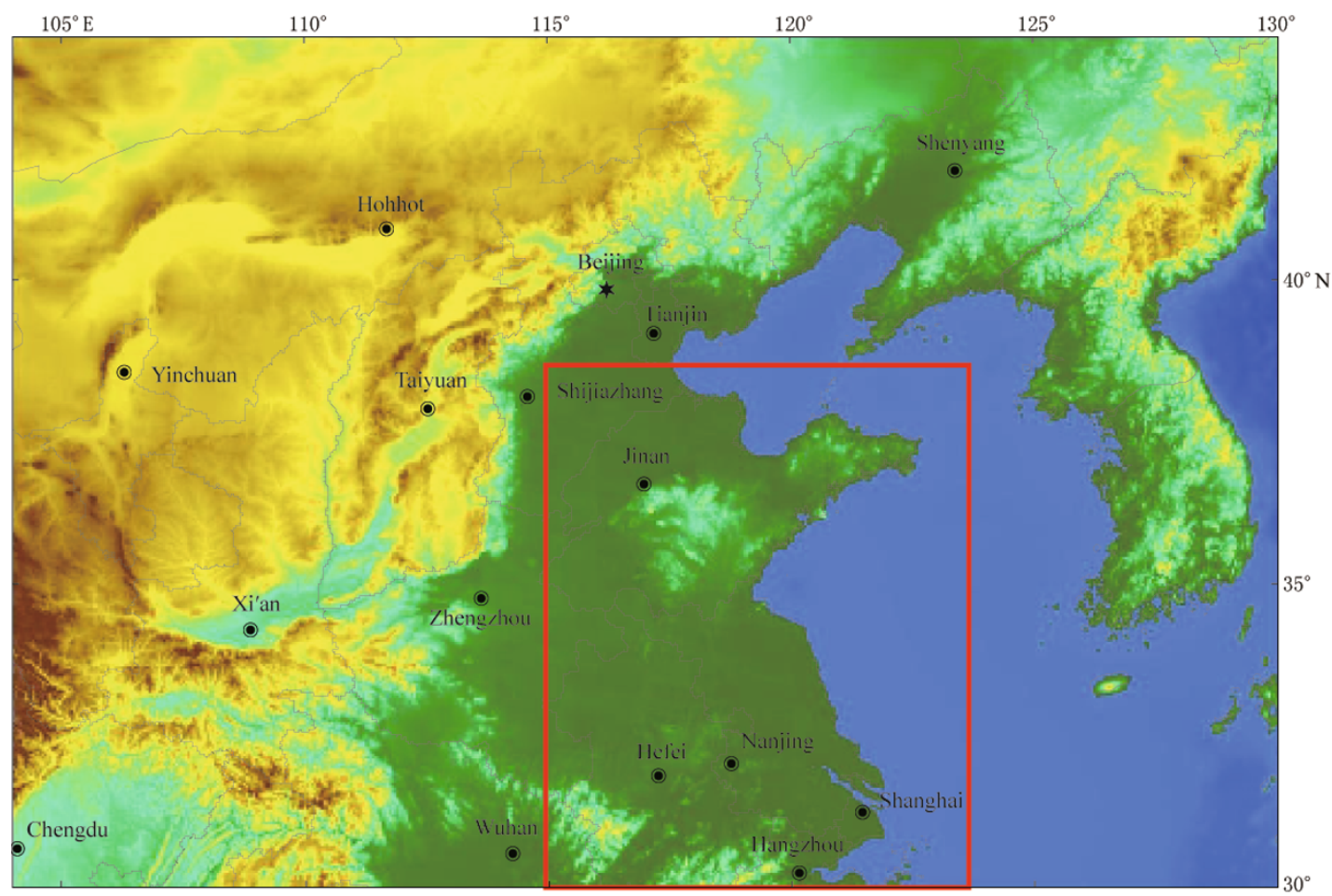

Figure 1 The surface topography and location of study region.

\subsection{Data processing}

When the confidence level is set as 95\%, the central value of confidence interval for quality factor is $Q_{\mathrm{m}}$. The half of the difference between the upper confidence limit and lower confidence limit is the residual scope for quality factors, i.e., $\delta Q_{\mathrm{m}}$. When $\delta Q_{\mathrm{m}} / Q_{\mathrm{m}}$ is lower than $30 \%$, the measurement precision is believed to be relatively high, and the result is credible. After selection, stations of high signal to noise ratio (SNR) and estimation precision for quality factors are 75 in number. Table 1 lists the basic information for these stations as well as waveform recordings which add up to 8774 from each station during the study period. Figure 2 shows the stations with high estimation precision, i.e., $Q_{\mathrm{m}}$ and the epicentral distribution applied in the study. All of 411 selected earthquake are categoried into five groups: four earthquakes with magnitude $M_{\mathrm{L}} 1.0$ 1.9, 195 earthquakes with magnitude $M_{\mathrm{L}} 2.0-2.9,173$ earthquakes with magnitude $M_{\mathrm{L}} 3.0-3.9,33$ earthquakes with magnitude $M_{\mathrm{L}} 4.0-4.9$, and six earthquakes with $M_{\mathrm{L}}$ 5.0-5.9. According to the above study result, $Q_{\mathrm{m}}$ can be obtained using the records of single-station to study the time variation characteristics of regional seismic wave dispersion attenuation. In addition, the mean value of $Q_{\mathrm{m}}$ obtained by each single-station recordings is also used to study the time variation characteristics of seismic wave dispersion attenuation.

An example is given for illustration data processing. Figure 3a refers to the vertical component wave of Huainan earthquake with $M_{\mathrm{L}} 2.6$ happened at 22:17:53 on June 3, 2001. The data were recorded by the Dingyuan station in Anhui province. The arrow shows the initial arrival of direct $\mathrm{P}$ - and $\mathrm{S}$-waves. The epicentral distance is $83 \mathrm{~km}$, and $\mathrm{Sg}-\mathrm{Pg}$ is $9.44 \mathrm{~s}$. Figure $3 \mathrm{~b}$ refers to waveform of 1000 points/s changed by the sampling rate of 50 points/s after resampling. Figure $3 c$ provide the waveform of the first cycle of the direct $\mathrm{P}$-wave. Figure 3d gives the distribution of relative delay of group velocity (represented by open circles, and the size is proportional to spectrum amplitude) and the fitted curve with respect to the specified frequency $(9.5 \mathrm{~Hz})$. The confidence interval for quality factors at $95 \%$ confidence level is $Q_{\mathrm{m}} \cdot \tau_{1}$ and $\tau_{2}$ are equal to 900 , 0.020557 , respectively. The fitting residual is 0.001 .

\subsection{Dispersion characteristics analysis}

The studied results of quality factor based on the S coda wave show that the longer the coda wave lasts, the bigger the quality factor is. Quality factor become bigger as the epicentral distance and the focal depth increase. Besides, quality factor has no obvious relation with earthquake magnitude (Liu et al., 2005, 2009; Cong et al., 2000; Nava et al., 1999; Kumar et al., 2005). 
Table 1 Basic information and data analysis for the 75 stations involved in the study

\begin{tabular}{|c|c|c|c|c|c|c|c|c|c|}
\hline No. & Station name & Code & $\begin{array}{c}\text { Time } \\
\text { intervals }\end{array}$ & $\begin{array}{l}\text { Earthquake } \\
\text { frequency }\end{array}$ & No. & Station name & Code & $\begin{array}{c}\text { Time } \\
\text { intervals }\end{array}$ & $\begin{array}{l}\text { Earthquake } \\
\text { frequency }\end{array}$ \\
\hline 1 & Xuyi, Jiangsu & $\mathrm{XY}$ & $2001-2009$ & $67^{*}$ & 39 & Boshan, Shandong & $\mathrm{BSH}$ & $2003-2011$ & $21^{\sharp}$ \\
\hline 2 & Suqian, Jiangsu & $\mathrm{SQ}$ & $2002-2009$ & $69^{*}$ & 40 & Changdao, Shandong & CHD & $2007-2011$ & $133^{\sharp}$ \\
\hline 3 & Xuzhou, Jiangsu & $\mathrm{XZ}$ & $2001-2007$ & $58^{*}$ & 41 & Chengwu, Shandong & CHW & $2007-2011$ & $2^{\sharp}$ \\
\hline 4 & Sucheng, Anhui & $\mathrm{SCH}$ & $2002-2009$ & $1861^{*}$ & 42 & Dongying, Shandong & DOY & $2007-2011$ & $18^{\sharp}$ \\
\hline 5 & Baisha, Anhui & BAS & $2007-2009$ & $60^{*}$ & 43 & Dushandao, Shandong & DSD & $2007-2011$ & $10^{\sharp}$ \\
\hline 6 & Feidong, Anhui, & FED & 2002-2004 & $39^{*}$ & 44 & Haihua, Shandong & HAH & $2007-2011$ & $4^{\sharp}$ \\
\hline 7 & Hefei, Anhui & HEF & $2001-2009$ & $184^{*}$ & 45 & Heze, Shandong & HEZ & $2006-2011$ & $11^{\sharp}$ \\
\hline 8 & Hanshan, Shandong & $\mathrm{HSH}$ & $2004-2009$ & $41^{*}$ & 46 & Jimo, Shandong & JIM & $2005-2011$ & $30^{\sharp}$ \\
\hline 9 & Dingyuan, Anhui & DYN & 2001-2009 & $84^{*}$ & 47 & Jiaxiang, Jiangsu & JIX & $2003-2011$ & $17^{\sharp}$ \\
\hline 10 & Tancheng, Shandong & $\mathrm{TCH}$ & $2007-2011$ & $108^{*}$ & 48 & Kenli, Shandong & KEL & $2007-2011$ & $23^{\sharp}$ \\
\hline 11 & Cangshan, Shandong & $\mathrm{CSH}$ & $2001-2011$ & $201^{*}$ & 49 & Laiyang, Shandong & LAY & $2005-2011$ & $6^{\sharp}$ \\
\hline 12 & Linmu, Shandong & LIS & $2007-2011$ & $113^{*}$ & 50 & Linqing, Shandong & LIQ & $2006-2011$ & $1^{\sharp}$ \\
\hline 13 & Junan, Shandong & JUN & $2007-2011$ & $123^{*}$ & 51 & Longkou, Shandong & LOK & $2007-2011$ & $14^{\sharp}$ \\
\hline 14 & Juxian, Shandong & JUX & $2007-2011$ & $122^{*}$ & 52 & Liangshan, Shandong & LSH & $2007-2011$ & $3^{\sharp}$ \\
\hline 15 & Yishui, Shandong & YSH & $2004-2011$ & $169^{*}$ & 53 & Niulan, Shandong & NLA & $2007-2011$ & $7 \sharp$ \\
\hline 16 & Wulian, Shandong & WUL & $2001-2011$ & $159^{*}$ & 54 & Pingdu, Shandong & PID & $2007-2011$ & $14^{\sharp}$ \\
\hline 17 & Anqiu, Shandong & ANQ & $2007-2011$ & $54^{*}$ & 55 & Qingdao, Shandong & QID & $2005-2011$ & $9^{\sharp}$ \\
\hline 18 & Ganyu, Shandong & GAY & $2003-2009$ & $4^{\sharp}$ & 56 & Xixia, Shandong & QIX & $2007-2011$ & $63^{\sharp}$ \\
\hline 19 & Guanyuan, Shandong & GUY & $2003-2009$ & $7^{\sharp}$ & 57 & Qufu, Shandong & QUF & $2007-2011$ & $12^{\sharp}$ \\
\hline 20 & Liuhe, Shandong & LH & $2001-2009$ & $22^{\sharp}$ & 58 & Rongcheng, Shandong & $\mathrm{RCH}$ & $2001-2011$ & $31^{\sharp}$ \\
\hline 21 & Liyang, Jiangsu & LY & $2001-2009$ & $22^{\sharp}$ & 59 & Rushan, Shandong & RSH & $2007-2011$ & $18^{\sharp}$ \\
\hline 22 & Nanjing, Shandong & NJ & $2001-2009$ & $15^{\sharp}$ & 60 & Shanghe, Shangdong & $\mathrm{SHH}$ & $2007-2011$ & $2^{\sharp}$ \\
\hline 23 & Nantong, Shandong & NT & $2001-2009$ & $113^{\sharp}$ & 61 & Taian, Shandong & TIA & $2003-2011$ & $9^{\sharp}$ \\
\hline 24 & Peixian, Jiangsu & $\mathrm{PX}$ & $2001-2009$ & $9^{\sharp}$ & 62 & Tangtou, Shandong & TAT & $2007-2011$ & $31^{\sharp}$ \\
\hline 25 & Sheyang, Jiangsu & SY & $2001-2009$ & $5^{\sharp}$ & 63 & Taozhuang, Shandong & $\mathrm{TZH}$ & $2003-2011$ & $23^{\sharp}$ \\
\hline 26 & Wuxi, Jiangsu & WX & $2001-2009$ & $11^{\sharp}$ & 64 & Wendeng, Shandong & WED & $2007-2011$ & $26^{\sharp}$ \\
\hline 27 & Xuwei, Jiangsu & XW & $2003-2009$ & $6^{\sharp}$ & 65 & Wenhai, Shandong & WEH & $2007-2011$ & $22^{\sharp}$ \\
\hline 28 & Yizheng, Jiangsu & $\mathrm{YZ}$ & $2006-2009$ & $4^{\sharp}$ & 66 & Wulongshan, Shandong & WLS & $2007-2011$ & $5^{\sharp}$ \\
\hline 29 & Zhenjiang, Shandong & ZJ & $2001-2009$ & $7^{\sharp}$ & 67 & Wenshang, Shandong & WSH & $2007-2011$ & $3^{\sharp}$ \\
\hline 30 & Changshu, Jiangsu & CS & $2001-2009$ & $140^{\sharp}$ & 68 & Xintai, Shandong & XIT & $2007-2011$ & $24^{\sharp}$ \\
\hline 31 & Bengbu, Shandong & BEB & $2007-2009$ & $9^{\sharp}$ & 69 & Yantai, Shandong & YTA & $2005-2011$ & $14^{\sharp}$ \\
\hline 32 & Luoeling, Anhui & $\mathrm{BZY}$ & $2002-2009$ & $1079^{\sharp}$ & 70 & Zoucheng, Shandong & $\mathrm{ZCH}$ & $2007-2011$ & $94^{\sharp}$ \\
\hline 33 & Foziling, Anhui & FZL & $2007-2009$ & $941^{\sharp}$ & 71 & Zhaoyuan, Shandong & ZHY & $2007-2011$ & $8^{\sharp}$ \\
\hline 34 & Huinan, Anhui & HNA & $2001-2009$ & $8^{\sharp}$ & 72 & Puyang, Henan & PY & $2005-2011$ & $4^{\sharp}$ \\
\hline 35 & Liuan, Anhui & LAN & $2002-2009$ & $51^{\sharp}$ & 73 & Qingfeng, Henan & $\mathrm{QF}$ & $2007-2011$ & $8^{\sharp}$ \\
\hline 36 & Lanniao, Anhui & LNA & $2007-2009$ & $940^{\sharp}$ & 74 & Jinshan, Shanghai & QHS & $2007-2009$ & $8^{\sharp}$ \\
\hline 37 & Qishan, Anhui & SJH & $2002-2009$ & $1079^{\sharp}$ & 75 & Jiaxing, Zhejiang & JAX & $2007-2009$ & $5^{\sharp}$ \\
\hline 38 & Beihuangcheng, Shandong & $\mathrm{BHC}$ & $2007-2011$ & $57^{\sharp}$ & & & & & \\
\hline
\end{tabular}

Note: the figures marked with $*$ refer to the earthquakes centering on the station with a radius of $100 \mathrm{~km}$. The figures marked with $\sharp$ refer to the scope of $30 \mathrm{~km}$.

According to the $\mathrm{P}$-wave dispersion recorded during the process of the local earthquakes, the $Q_{\mathrm{m}}$ also becomes larger as the epicentral distance and focal depth increase, showing a liner variation tendency in statistics (Liu et al., 2005, 2009). Therefore, in order to analyze the background field of quality factor and to search for the relation of spatio-temporal characteristics during the earthquake gestation process, the influence of different epicentral distances and focal depths on quality factors should be removed. For such considerations, we put forward the use of unit pseudo wave travel time, i.e., $Q_{\mathrm{mSP}}$, that is, the actually measured $Q_{\mathrm{m}}$ divide the travel time difference of $\mathrm{Sg}-\mathrm{Pg}$ so as to study the spatio-temporal variation characteristics of seismic wave dispersion attenuation. Figure 4 shows the isoline distribution of mean value of $Q_{\mathrm{mSP}}$ for total 75 stations in consideration. Figure 5 provides the $Q_{\mathrm{mSP}}$ variation with time for total 75 stations. Figure 5 also gives the $Q_{\mathrm{mSP}}$ variation with time for specified station.

From Figure 4 it can be seen that $Q_{\mathrm{mSP}}$ in the southern part of Tanlu fault zone (about $31.5^{\circ} \mathrm{N}-36.5^{\circ} \mathrm{N}$ ) is relatively low in space. And the lowest 


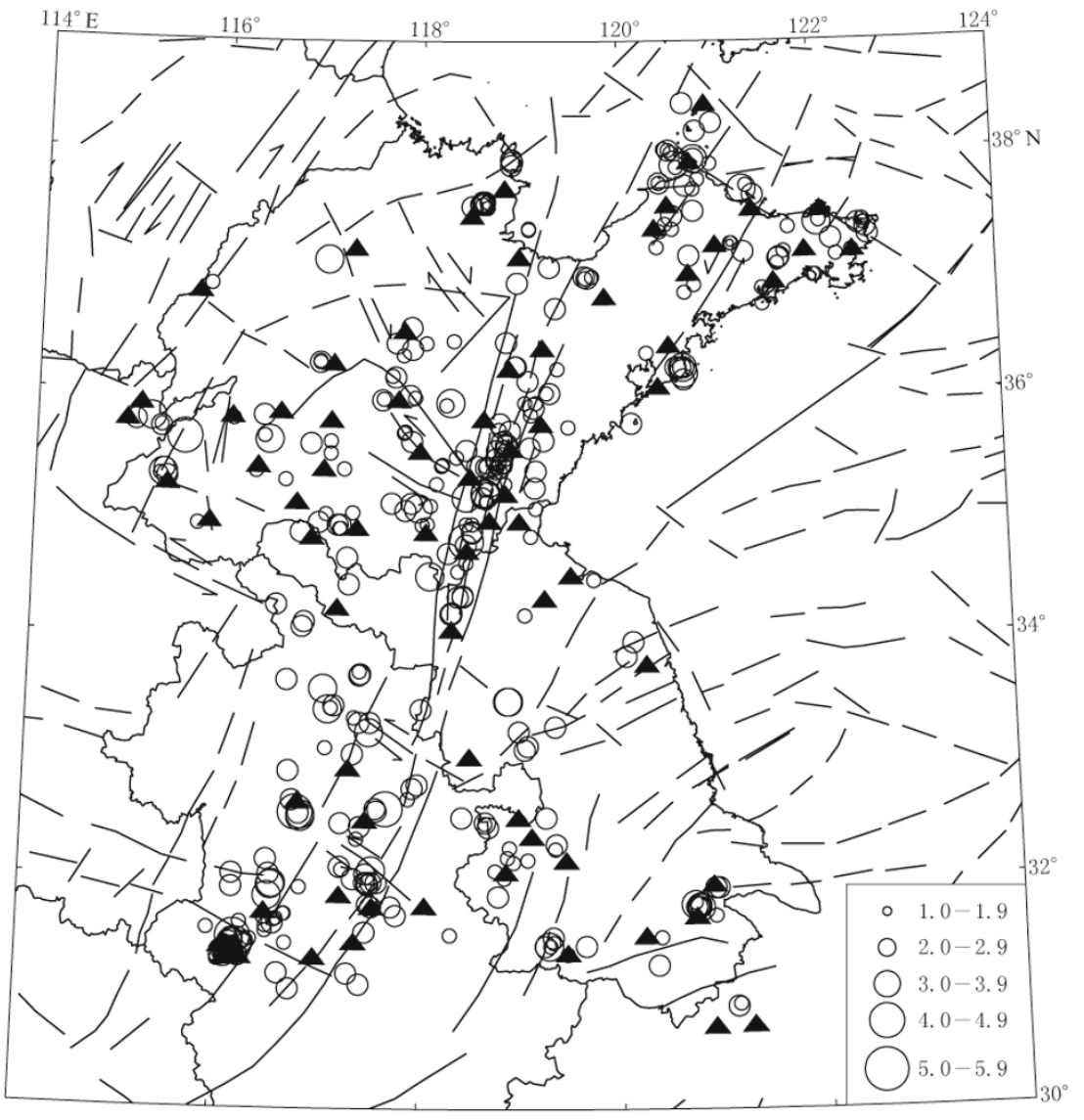

Figure 2 Distribution of seismic stations (triangles) and earthquakes (circles) used.
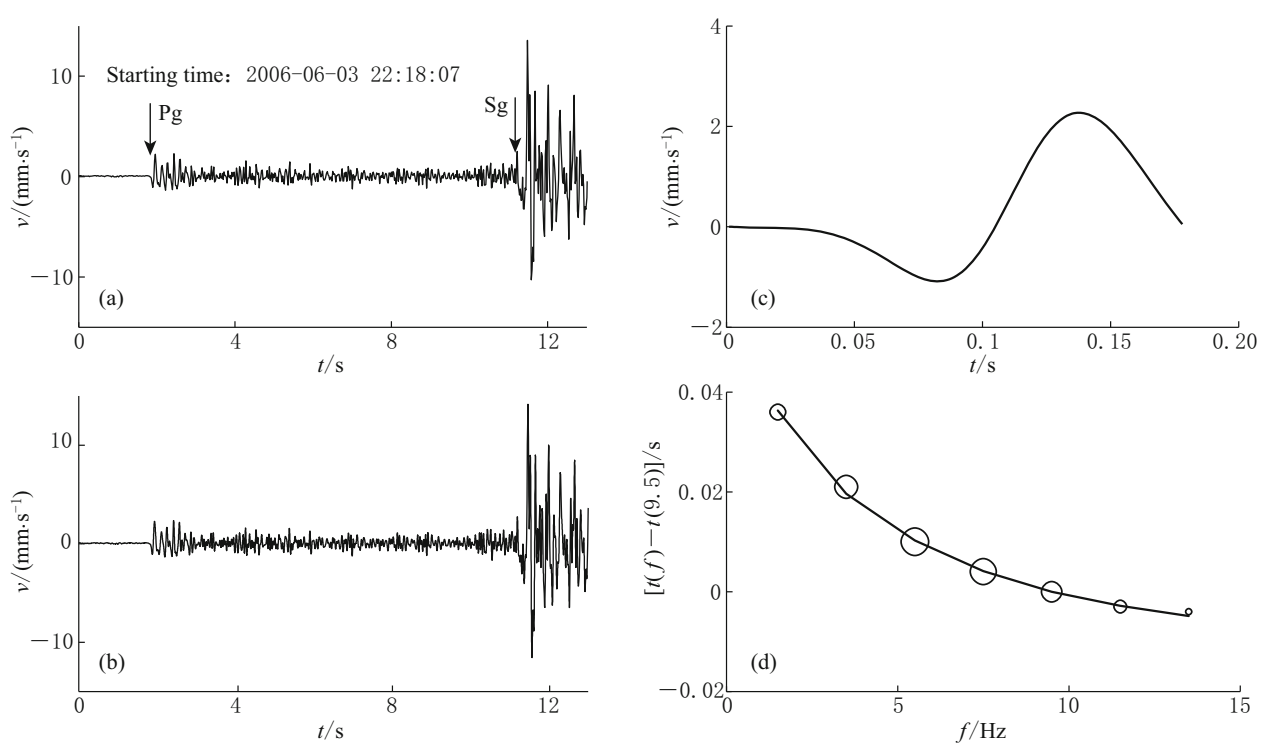

Figure 3 Seismic waveform, resampling waveform, the first cycle period signal, relative group velocity delay after filtering and fitted curve parameters. (a) Seismogram of a M2.6 earthquake at 18:07 on 3 June, 2006 recorded by HUN station with a sampling rate of $0.02 \mathrm{sps}$, the arrow denotes the arrival time of direct P- and S- waves. (b) Resampled seismogram for event recoded by HUN station with a sampling interval of $0.001 \mathrm{sps}$. (c) The first full cycle of the Pg wave in the seismogram of (b). (d) Observed dispersion of spectral components of the first full cycle of the $\mathrm{P}$ wave in the seismogram of (b). The open circles indicate dispersion from (b) signals. The diameters of the open circles are proportional to observed spectral amplitudes. The line indicates fitting curve. 


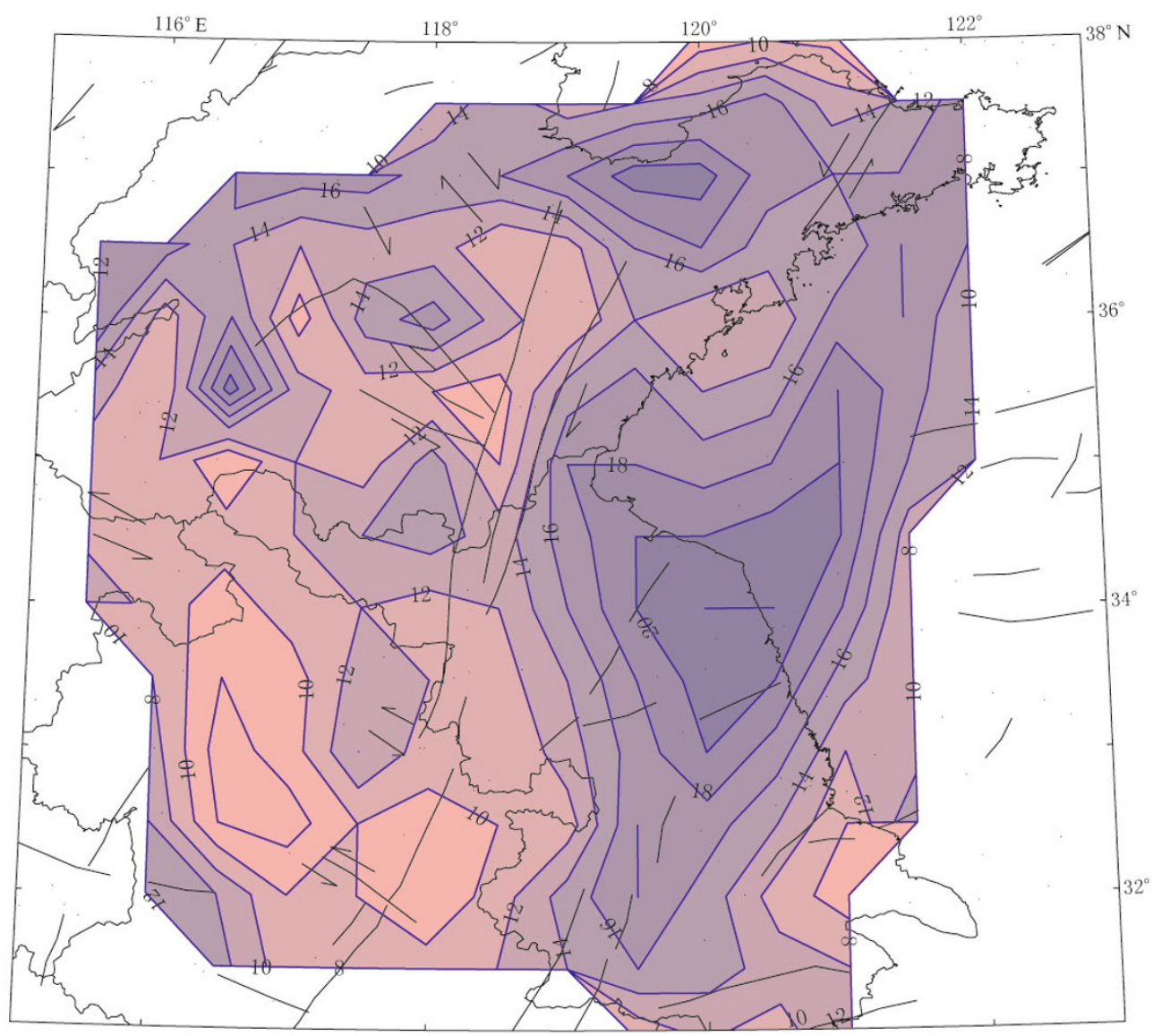

Figure 4 The isoline distribution of mean value of $Q_{\mathrm{mSP}}$ for total 75 stations.

distribution area lies in the epicenter of the Tancheng earthquake with $M 8.5$ in 1668 and the area south to $32.5^{\circ} \mathrm{N}$. Whereas, in the Tancheng-Suqian section $\left(34.0^{\circ} \mathrm{N}-34.6^{\circ} \mathrm{N}\right)$ it is quite high in space, and $Q_{\mathrm{mSP}}$ in the east side of the Tanlu fault zone is generally higher than those within the zone and in the west side. Furthermore, $Q_{\mathrm{mSP}}$ in the west side of Tanlu fault zone is generally higher than that within the belt. From Figure 5 it can be observed that before $2006, Q_{\mathrm{msP}}$ in the studied area varied at a relatively low level. From the

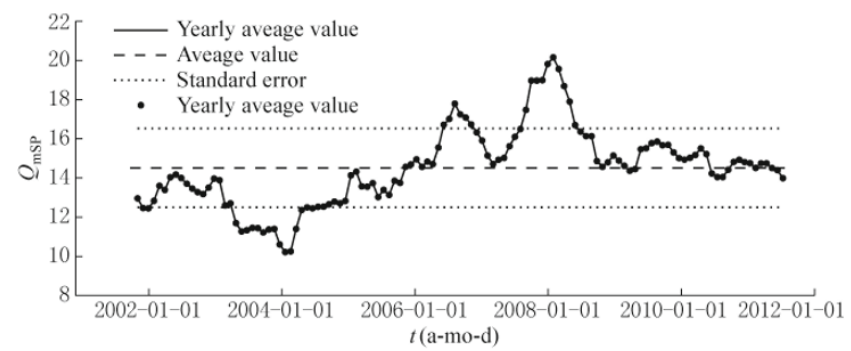

Figure $5 \quad Q_{\mathrm{mSP}}$ variation with time for total 75 stations (gilding window length is one year, and gliding steplength is one month). second half of 2006 to the first half of 2008, the rising fluctuation was once observed. Since the second half of 2008, $Q_{\mathrm{mSP}}$ in the studied area is relatively stable with time. And from Figure 6, it can be seen that the physical properties are stable for stations in the Tanlu fault zone and on its both sides.

\section{Discussion and conclusions}

1) Tanlu fault zone is a typically deep and steep slip fault zone in the eastern part of China. The cutting depth is from shallow to deep and finally cuts through the lithosphere. Since the Middle Pleistocene (the new tectonic period, i.e., from 0.73 Ma BP to now), the cutting depth has reached 80-100 km (Wan, 1996), and the width in the middle part of the fault zone is from 40 to $60 \mathrm{~km}$. The inner structure is quite complicated, consisting of four mutually parallel main faults and thus forming a structure of graben on both sides and horst in the middle part. Each main fault is from tens of meters to over a hundred meters in width. And the fault surface is quite complicated, displaying the characteristics 

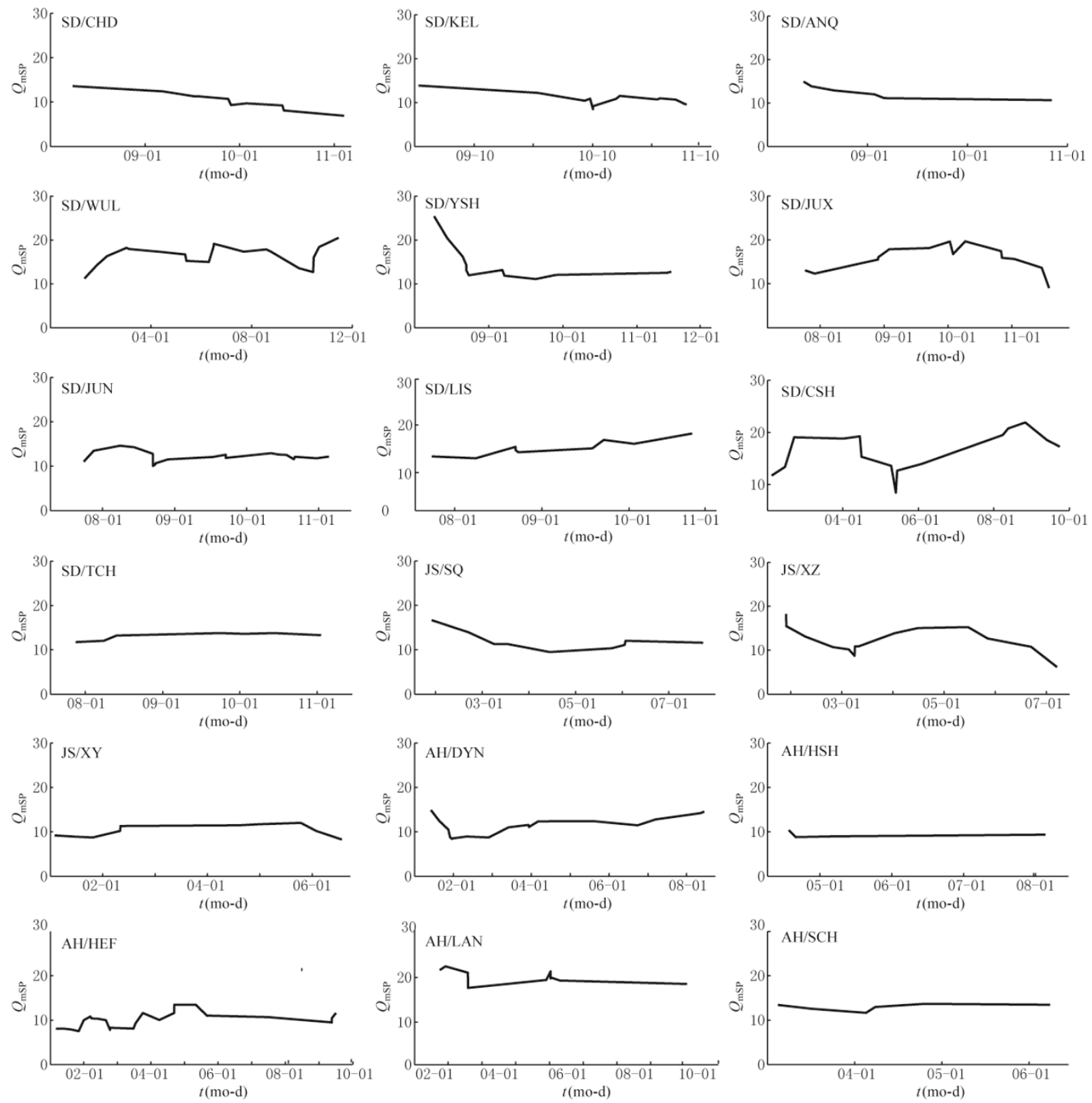

Figure 6 Temporal variations of $Q_{\mathrm{mSP}}$ for some specific stations.

of multi-period tectonic movements. The surface is narrow from the middle part to the south and north tips of the fault zone and becomes single graben structures with only two main fault controls. The faulting activities have clear characteristics in different sections due to the extrusion stress at aproximatly ENE $65^{\circ}-70^{\circ}$ formed by the subduction of the Pacific plate to the Eurasian plate as well as the common control of tension force field at about $\mathrm{NNW} 155^{\circ}-160^{\circ}$ in the large area from Baikal via the Great North China to the Ryukyu trench (Xu and Zhao, 2007). The Weifang-Jiashan section is mainly developed in the Quaternary. And new fault- ing activities are featured by extrusion thrust and dextral strike slip. In the history, the 70 B.C. M7.0 Anqiu and 1668 M8.5 Tancheng earthquakes occurred in this segment without any moderate earthquakes (e.g., magnitude range of 5.0-6.0). Therefore, this section was characterized by strong seismic activities in low frequency (Li, 1992). The great scale geological mapping found that the Weifang-Jiashan section has three independent fracture sections, that is, the Anqiu fracture section (about $100 \mathrm{~km}$ long), the Juxian-Tancheng fracture area (about $130 \mathrm{~km}$ long) and the Xinyi-Sihong fracture section (about $130 \mathrm{~km}$ long). The two main areas of obsta- 
cle signs are Maobu to Guanshuai, Yaoshang to Maipo, respectively (Li et al., 1994; Chao et al., 1995). In the Juxian-Tancheng section, besides the earthquake with M8.5 in the Holocene epoch, there were three earthquakes in ancient times. The reoccurrence period for strong earthquakes is about $3500 \mathrm{a}$ in average. The modern small earthquakes are intensive to form the belt. There were three ancient earthquakes in the Holocene epoch in the Xinyi-Sihong section. The latest ancient earthquake is about $3510-4960$ a before and the reoccurrence interval is about 4000 a for great earthquakes. The modern small earthquake activities are weak. According to the study results, the Xinyi-Sihong section is already at the later stage of locking fault and is a section with great danger for future strong earthquake. On the contrary, the Anqiu section is not so dangerous and the Juxian-Tancheng section is at the adjusting stage after the quake with small possibility for great earthquakes (Li et al., 1994; Chao et al., 1997).

2) Strong earthquakes are the results of rock sudden failure when the stress in the deformed discontinuous sections accumulate to exceed the strength of rock. Along the boundary zone, because of strong differential movements in both sides, it is easy to cause the greatest discontinuity in tectonic deformation, which is most conducive to stress accumulation and thus to strong earthquakes. The deformation and movement of active block are the main reason for the gestation and occurrence of strong earthquakes in the Chinese mainland (Zhang et al., 2003). The mode of deformation in active block is determined by properties of the media (e.g., fault substance, surrounding rock, and interaction of water and rock), mechanical conditions (e.g., the stress size, direction and loading rate), rock mass structure (e.g., the integrated structure of the fault surface, obstacles, and recombination of faults) and environmental conditions (e.g., confining pressure, temperature, pore pressure, water and hydrochemistry environment). The reason that an earthquake takes place in a certain location is owing to the mechanical disturbance in some positions which is caused by two reasons. One is the variation in the outer driving force and the other is the changes in the deformation of other tectonic position (Ma et al., 1995). The studies have proved that both the attenuation and modulus of saturated rocks vary with the porous fluid content and the viscosity coefficient. The attenuation and dispersion of dry sandstones increase as the porosity increase (Xi et al., 1997). The quality factors (or attenuation) of $\mathrm{P}$ - and S-waves and permeability present obviously a logarithm relation
(Li et al., 2001). The porous heterogeneous structure is a major reason for attenuation of medium- and lowfrequency seismic waves in actual strata rocks (Liu et al., 2010). The measured mean value $Q_{\mathrm{mSP}}$ for each station reflects the heterogeneity and inelasticity degrees of regional media (P- and S- waves). From Figure 4 it can be observed that the quality factors in actively tectonic area are higher than those in stable tectonic area. In the Juxian-Tancheng section, the attenuation of seismic waves are relatively rapid and quality factors of media are relatively small, reflecting the large heterogeneity and strong inelasticity deformation of the media as well as the sensitivity to changes in outer mechanical conditions. Deformation instability is easy to appear and the occurrence frequency of small earthquake is high in local area. According to the earthquake pattern of fault locking $\rightarrow$ stick slip earthquake $\rightarrow$ adjustment after the earthquake $\rightarrow$ fault relocking (Chao et al., 1997), at present, the Juxian-Tancheng section is still at the stage of adjustment after the quake, showing no stress accumulation caused by relocking. However, in the Xinyi-Sihong section, attenuation of seismic waves is slow and quality factors of the media is high, which is insensitive to changes in outside mechanical conditions and have few small earthquakes. Thus, the fault is already at the locking stage. From the point of view of long term, the section has already been under the similar tectonic conditions and deep environment for the strong earthquakes happening in Tancheng in 1668. The studied results by Li et al. (2008) it is largest for velocity in the depth range of upper and middle crust in the western, middle in eastern and lowest in central south section of Tanlu fault zone. The velocity structure distribution obtained from the spatial distribution characteristics of $Q_{\mathrm{mSP}}$ in the study is basically similar to the study result by Li et al. (2001). The variation of $Q_{\mathrm{mSP}}$ with time in each station reflects the variation in outside mechanical conditions. According to the pattern of strong earthquakes developed by Chao et al. (1997), $Q_{\mathrm{mSP}}$ is expected to display an abnormal variation process of increase $\rightarrow$ decrease $\rightarrow$ another increase. The time variation of $Q_{\mathrm{mSP}}$ in Figure 5 indicates that after the earthquake with M9.0 on March 11, 2011, the regional background stress field in the studied area has not displayed any traces of increase. Therefore, in a short and medium period, it is scarcely possible to occur strong earthquake in the Tanlu fault zone. In Figure 5, from the second half of 2006 to the first half of 2008, the rising fluctuation variation of $Q_{\mathrm{mSP}}$ was observed. The preliminary analyses suggest that 
it may be related to the adjustment of regional stress field caused by the Jiujiang earthquake with M5.7 on November 26, 2005 in the southern extension part of the Tanlu fault zone, namely, the tectonic integration area of the Tongbai-Dabie fault zone, the Jiangnan fault zone and the Yangtze swelling and sinking belt, the Wen'an earthquake with M5.1 on July 4, 2006 and the Wenchuan earthquake with $M_{\mathrm{S}} 8.0$ on May 12, 2008. The time variations of $Q_{\mathrm{mSP}}$ in the 18 stations (along the distribution of the central south section of Tanlu fault zone and its surrounding area) indicate that it is much less possible to occur strong earthquakes in the central south section of the Tanlu fault zone.

3) To eliminate the influence of the epicentral distance and depth the paper adopts $Q_{\mathrm{msp}}$ to express time and space characteristics of media, which is more stable compared with the absolute $Q$ value.

Acknowledgements The study is supported by National Natural Science Foundation of China (grant No. 40974031), Shandong Provincial Natural Science Foundation (grant No. Y2007E09) and Jiangsu Provincial Social Development Project (grant No. BE2009691).

\section{References}

Chao H T, Li J L, Cui Z W and Zhao Q Y (1997). Mode of motion of the holocene fault in Weifang-Jiashan segment of the Tanlu fault zone and earthquake generating model. J Seism Res 20(2): 218-226 (in Chinese with English abstract).

Chao H T, Li J L, Cui Z W, Man H M and Du X S (1995). Active faults in Tanlu (Tancheng-Lujiang) Fault Zone and the hazards produced by the 1668 Tancheng earthquake $(M=8.5)$. Marine Geology and Quaternary Geology 15(3): 69-80 (in Chinese with English abstract).

Cong L, Mejia J and Mitchell B J (2000). Attenuation dispersion of $\mathrm{P}$ waves in and near the New Madrid seismic zone. Bull Seismol Soc Am 90(3): 679-689.

Correig A M and Mitchell B J (1989). Attenuative dispersion at La Cerdanya, eastern Pyrenees. Phys Earth Planet Inter 57: 304-310.

Feng D Y (1981). Seismic Wave Velocity Anomaly. Seismological Press, Beijing, 21-33 (in Chinese).

Gao J H and Yang S L (2007). A method study of media quality factor assessment by use of the zero offset VSP data. Chinese J Geophys 50(4): 1 198-1 209 (in Chinese with English abstract).

Hao S B, Qin J X and Wu X Y (2009). A summary of the progress in the study of seismic quality factor $Q$. Progress in Geophysics 24(2): 375-381 (in Chinese with English abstract).
Institute of Geology, State Seismological Bureau (1987). The Tanlu Fault Zone. Seismological Press, Beijing, 15-107 (in Chinese).

Kumar N, Parvez I A and Virk H S (2005). Estimation of coda wave attenuation for NW Himalayan region using local earthquakes. Phys Earth Planet Inter 151: 243-258.

Li J L (1992). The active faults in the Tanlu fault zone and the structural conditions of the Tancheng earthquake $(M=8.5)$. Shandong Geology 8(1): 40-52 (in Chinese with English abstract).

Li J L, Chao H T, Cui Z W and Zhao Q Y (1994). Segmentation of active fault along the Tancheng-Lujiang Fault Zone and evaluation of strong earthquake risk. Seismology and Geology 16(2): 121-126 (in Chinese with English abstract).

Li Q H, Huang Y, Zhang Y S, Fan X P, Jin S M and Xiong $Z$ (2008). Velocity structure characteristics of the central south section in the Tanlu fault zone. Recent Developments in World Seismology (1): 110 (in Chinese).

Li Y L, He Z H, Huang D J, Shan Y M, Chen X C and Zhou A B (2001). Relation between rock porosity permeability property and seismic wave attenuation and propagation velocity. Natural Gas Industry 21(4): 7-11 (in Chinese with English abstract).

Liu H, Anderson D L and Kanamori H (1976). Velocity dispersion due to anelasticity: Implication for seismology and mantle composition. Geophys J R astr Soc 47: 4158.

Liu J, Ba J, Ma J W and Yang H Z (2010). Analysis of seismic wave attenuation in random porous media. Scientia Sinica Phys, Mech \& Astron 40(7): 858-868 (in Chinese with English abstract).

Liu X Q, Chen C H, Zhou Y W and Qu J H (2009). Intrinsic and attenuative dispersion characteristics of direct $\mathrm{P}$-waves in and near the source area of the $1999 M_{\mathrm{W}} 7.6$ Chi-Chi, Taiwan, earthquake before and after the mainshock. Earthquake Science 22(1): 33-44.

Liu X Q, Sun Q W, Li H, Shi Y Y, Ji A D and Wang F J (2005). Variation of $Q$ value before and after the 1999 Xiuyan, Liaoning Province, $M=5.4$ earquake on the basis of analysis on attenuation dispersion of $\mathrm{P}$ waves. Acta Seismologica Sinica 18(5): 510-520.

Ma J, Ma S L and Liu L Q (1995). The stage of anomalies before an earthquake and the characteristics of the spatial distribution. Seismology and Geology 17(4): 363-371 (in Chinese with English abstract).

Nava F A, Arthur R G, Castro R R, Suarez C, Marquez B, Cornu F N, Saavedra G and Toscano R (1999). S wave attenuation in the coastal region of Jalisco-Colima, Mexico. Phys Earth Planet Inter 115: 247-257.

Qi C J (2005). Algorithm Analysis and Application of Digital Signal Processing Techniques. China Machine Press, Beijing, 69-96 (in Chinese).

Trong P H and Granet M (1980). Body-wave dispersion in 
the Friuli focal area. Phys Earth Planet Inter 21: 31-37.

Wan T F (1996). Extension and cutting depth of the Tanlu fault zone. Geoscience 10(4): 518-525 (in Chinese with English abstract).

Wang B Z, Zhu Y and Wang D (2008). The fluid mechanism model of porous media and its dispersion mechanism. Progress in Exploration Geophysics 31(6): 405-413 (in Chinese with English abstract).

Wang Z and Nur A (1990). Dispersion analysis of acoustic velocities in rocks. J Acous Soc Amer 87(6): 2 384-2 395.

White J E (1975). Computed seismic speeds and attenuation in rocks with partial gas saturation. Geophysics 40(2): 224-232.

Xi D Y, Liu B, Cheng J Y and Liu W (1997). The attenuation and dispersion of dry and saturated Rocks. Computing Techniques for Geophysical and Geochemical Explo- ration 19(1): 19-22 (in Chinese with English abstract).

Xu J R and Zhao Z X (2007). Study on characteristics of lithospheric stress field,tectonic motions and its exhumation mechanism of the ultrahigh-pressure metamorphic belt in and around the Sulu-Dabie orogenic belt. Acta Petrologica Sinica 23(12): 3 317-3 324 (in Chinese with English abstract).

Zhang P Z, Deng Q D, Zhang G M, Ma J, Gan W J, Min W, Mao F Y and Wang Q (2003). Strong earthquakes activity and active block in the Chinese Mainland. Science in China (Series D) 33(Suppl.): 12-20 (in Chinese with English abstract).

Zhang P, Wang L S, Zhong K and Ding Z Y (2007). Research on the segmentation of Tancheng-Lujiang Fault Zone. Geological Review 53(5): 586-591 (in Chinese with English abstract). 